\title{
Immunotherapy of patient with hepatocellular carcinoma using cytotoxic T lymphocytes ex vivo activated with tumor antigen-pulsed dendritic cells
}

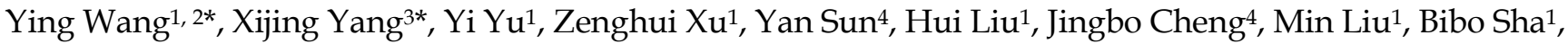 \\ Linfang $\mathrm{Li}^{1}$, Na Ding ${ }^{4}$, Zhong Li ${ }^{4}$, Huajun Jin ${ }^{1 凶}$, Qijun Qian ${ }^{1,3,4,5 \bowtie ~}$ \\ 1. Department of Gene and Viral Therapy Laboratory, Shanghai Eastern Hepatobiliary Surgery Hospital, Shanghai, 200438, China; \\ 2. Department of Life Science and Technology, Tongii University, Shanghai, 200092, China; \\ 3. Department of Biotherapy, Shanghai Eastern Hepatobiliary Surgery Hospital, Shanghai, 200438, China; \\ 4. Shanghai Cell Therapy Research Institute, Qianyang Road 75A, Shanghai, 201805, China; \\ 5. Ningbo $5^{\text {th }}$ Hospital (Ningbo Cancer Hospital), Zhuangshi Avenue 1166, Ningbo, 315201, China. \\ * These authors contributed equally to this work \\ $\triangle$ Corresponding authors: Emails: qianqj@sino-gene.cn, hj-jin@hotmail.com \\ ( $)$ Ivyspring International Publisher. This is an open access article distributed under the terms of the Creative Commons Attribution (CC BY-NC) license \\ (https://creativecommons.org/licenses/by-nc/4.0/). See http://ivyspring.com/terms for full terms and conditions.
}

Received: 2017.07.31; Accepted: 2017.10.06; Published: 2018.01.01

\begin{abstract}
Purpose The aim of this study was to evaluate the clinical response of immunotherapy with dendritic cell-cytotoxic T lymphocytes (DC-CTLs) in patients with hepatocellular carcinoma (HCC).

Method Sixty-eight patients with a confirmed diagnosis of HCC and who received follow-up until December 2015 were enrolled. We measured immune phenotypes of DCs and activated T cells using flow cytometry and clinical indexes using an electrochemiluminescence method.

Results DCs exhibited up-regulation of the maturation markers CD83, CD80, CD1 lc, and CD86 on day8. Levels of IFN- $\gamma$ and TNF- $\alpha$ were higher in the DCs pulsed with tumor-associated antigens (TAAs) than in DCs with a non-proliferative recombinant adenovirus. The percentage of regulatory $T$ cells (Tregs) decreased in patients after DC-CTLs therapy. In addition, serum levels of AFP, AFP-L3, ALT, and CA19-9 were significantly reduced in these patients. Quality of life was improved, especially on physical functioning scales. Median overall survival (OS) and progression-free survival (PFS) were 8.2 months and 4.3 months, respectively, for the control group and 12.8 months and 9 months, respectively, for the DC-CTL group. Patients treated with DC-CTLs therapy showed a statistically significant PFS and OS curve (OS: $p=0.016$; PFS: $p<0.0001$ ). In addition, no serious adverse reactions were observed.

Conclusion This study indicated that Tregs, as well as serum levels of AFP, AFP-L3, ALT, and CA19-9, which were correlated with a poor prognosis, decreased after DC-CTL treatments. The OS, PFS and the quality of life of HCC patients partially improved.
\end{abstract}

Key words: Dendritic cell-cytotoxic T lymphocyte, immunotherapy, Treg, quality of life.

\section{Introduction}

HCC is one of the most common malignant cancers in China, which accounts for approximately $90 \%$ of all primary liver cancers (PLC). Surgery, orthotopic liver transplantation (OLT), hepatic-artery chemoembolization (TACE), percutaneous intra-tumor ethanol injection (PEI), hepatic artery ligation (HAL) with catheterized chemotherapy, and molecularly targeted therapy are the common therapeutic treatments for HCC [1, 2]. However, treating HCC remains difficult and challenging. Sorafenib has been shown to improve survival in the treatment of HCC. However, only a limited number of patients have responded beneficially [3]. Prognosis of HCC remains poor, and HCC-related mortality is high [4].

Nowadays, immunotherapy using DC-based 
antigen-specific CTLs has been used in clinical trials for the treatment of various malignant tumors [5-7]. DCs from the peripheral blood of patients were transfected with recombinant adenoviruses containing TAAs and produced high levels of IL-12 in response. Mature DCs co-cultured with $\mathrm{T}$ cells induced the activation of CTLs and promoted a tumor-killing effect of antigen-specific $T$ cells that may provide effective adjuvant therapy for malignant tumors. Several studies have focused on the study of DC-based antigen-specific immunotherapy for HCC. Bray investigated the response of AFP-derived peptide-pulsed DC on immunity in patients with HCC [8]. Pardee compared the efficacy of antigen-specific CD8+ and CD4+ $\mathrm{T}$ cells using different forms of AFP fragments [9]. Zhou et al. used Hep3B cells that were transduced with recombinant adenoviruses carrying a human IFN- $\alpha$ promoter and an IFN- $\gamma$ gene to improve the effect of tumor-specific CTL against HCC [10]. O'Beirne et al. assessed the function of GPC-3 specific T cells in HCC [11]. Moreover, DC-CTLs therapy additionally held promise for the treatment of other malignant tumors, including non-small cell lung cancer (NSCLC) [12] and prostate cancer [13].

Therefore, it is important to determine the appropriate TAAs for DC activation and DC-CTLs therapy [14]. Several TAAs, such as TP53, Survivin, human telomerase reverse-transcriptase (hTERT), WT-1, and VEGFR2, frequently express on the cell surface of many malignant cancers including HCC and have been identified as promising TAAs for $T$ cell recognition or DC-based immunotherapy [15-18]. Although TAAs, including TP53, hTERT, and Survivin, have been used as DC vaccines in clinical trials against tumors [19-21], it is still uncertain whether these antigen-primed DCs can be used for enhancing the response of CTLs in patients with HCC.

During our prophase research [22], we preliminary evaluated the changes of Tregs, MDSCs, AFP, CA19-9, CA242 and CA724 in five malignant tumors. To further study the comprehensive potential value of DC-CTL therapy for HCC patients, we investigated the activities of expanded and activated DCs and CTLs; analyzed the changes in the serological index and levels of CD3, CD4, CD8 and Tregs; and assessed the clinical response of OS, PFS and quality of life in HCC patients treated with DC-CTLs therapy.

\section{Materials and Methods}

\section{Patients}

A total of 42 pathologically diagnosed HCC patients have signed informed consent forms approved by the Department of Health of Chinese PLA, and they received immunotherapy at Eastern Hepatobiliary Surgery Hospital from January 2012 to December 2014.Twenty-six other patients, who were enrolled as control group, did not receive DC-CTLs immunotherapy. The study is non-randomized because we don't have enough patients to be randomized into two arms at the same time. The inclusion criteria included as follows: $\mathrm{HCC}$

1) The diagnosis was confirmed by pathology of

2) Difficult or refusal to undergo surgery

3) Child-Pugh score $<=9$ (Class A or B)

4) Clinical Oncology Group Eastern (ECOG) score of 0,1

5) Liver, kidney and blood tests meet the following criteria:

WBC $>4 \times 10^{9} / \mathrm{L}$, Neutrophils cells $>1 \times 10^{9} / \mathrm{L}$, Lymphocyte cells $>1 \times 10^{9} / \mathrm{L}$, Hemoglobin $>=100 \mathrm{~g} / \mathrm{L}$ and Platelet $>=80 \times 10^{9} / \mathrm{L}$. The prothrombin time is in a reference range or not extends for more than 3 seconds. Urea nitrogen and serum creatinine do not exceed 1.5 times of the upper limitation.

6) Sign the informed consent form before joining into this study.

Patients were excluded from the study based on the following criteria:

1) Autoimmune disease or organ transplant history undergoing immunosuppressive therapy

2) Human immunodeficiency virus (HIV) infection, syphilis infection culture

3) Image evidence of positive or infected blood

4) Cell therapy allergies history, cytokines (such as interleukins) allergic history

5) Uncontrolled heart, lung, kidney, digestion, nerve, metabolism, infectious diseases, mental illness, etc. or other serious diseases

6) Pregnant women

As shown in Table 1, 16 patients $(n=5$ in the control group; $n=11$ in the DC-CTL therapy group) underwent adjuvant radiation treatment, and 52 patients $(n=21$ in the control group; $n=31$ in the DC-CTL therapy group) received TACE therapy.

\section{Construction and production of recombinant adenoviruses that encode tumor-associated antigens}

A replication-defective adenovirus containing the expression cassette of the required TAAs (TP53, hTERT and Survivin) was constructed, purified, and titrated according to the procedure described previously [23]. In brief, each expression cassette of the TAA was inserted into the shuttle vector of the recombinant adenoviral system and placed into the E1 
region of the adenoviral genome. Then, the recombinant adenoviruses were purified by high-performance liquid chromatography. Titers of the purified adenoviruses were determined by plaque assays of the tissue culture infectious dose 50 methods and shown as plaque-forming units per milliliter $(\mathrm{pfu} / \mathrm{ml})$. The sequences of TP53, hTERT and Survivin are recorded in Supplementary Table S1.

Table 1. Demographics and clinical characteristics

\begin{tabular}{|c|c|c|c|c|}
\hline & $\begin{array}{l}\text { Cases }(\%) \\
(\mathrm{n}=68)\end{array}$ & $\begin{array}{l}\text { Control group }(\%) \\
(\mathrm{n}=26)\end{array}$ & $\begin{array}{l}\text { DC-CTL group } \\
(\%)(n=42)\end{array}$ & P-Value \\
\hline Sex & & & & 0.745 \\
\hline Male & $59(86.8 \%)$ & $23(88.5 \%)$ & 36 (85.7\%) & \\
\hline Female & $9(13.2 \%)$ & $3(11.5 \%)$ & $6(14.3 \%)$ & \\
\hline Age & & & & 0.720 \\
\hline$<57$ & $40(58.8 \%)$ & $16(61.5 \%)$ & $24(57.1 \%)$ & \\
\hline$>=57$ & $28(41.2 \%)$ & $10(38.5 \%)$ & $18(42.9 \%)$ & \\
\hline Median (range) & $57(27-80)$ & $52(30-80)$ & $57(27-78)$ & \\
\hline Radiotherapy & & & & 0.511 \\
\hline Yes & $16(23.5 \%)$ & $5(19.2 \%)$ & $11(26.2 \%)$ & \\
\hline No & $52(76.5 \%)$ & $21(80.8 \%)$ & $31(73.8 \%)$ & \\
\hline TACE therapy & & & & 0.511 \\
\hline Yes & $52(76.5 \%)$ & $21(80.8 \%)$ & $31(73.8 \%)$ & \\
\hline No & $16(23.5 \%)$ & $5(19.2 \%)$ & $11(26.2 \%)$ & \\
\hline T stage & & & & 0.596 \\
\hline $\mathrm{T} 2$ & $11(16.2 \%)$ & $3(11.5 \%)$ & $8(19.0 \%)$ & \\
\hline T3 & 49 (72.1\%) & $19(73.1 \%)$ & $30(71.4 \%)$ & \\
\hline $\mathrm{T} 4$ & $8(11.8 \%)$ & $4(15.4 \%)$ & $4(9.5 \%)$ & \\
\hline $\mathrm{N}$ stage & & & & 0.811 \\
\hline No & $42(61.8 \%)$ & $17(65.4 \%)$ & $25(59.5 \%)$ & \\
\hline N1 & $22(32.4 \%)$ & $8(30.8 \%)$ & $14(33.3 \%)$ & \\
\hline N2 & $4(5.9 \%)$ & $1(3.8 \%)$ & $3(7.1 \%)$ & \\
\hline M stage & & & & 0.128 \\
\hline M0 & 49 (72.1\%) & $16(61.5 \%)$ & $33(78.6 \%)$ & \\
\hline M1 & $19(27.9 \%)$ & $10(38.5 \%)$ & $9(21.4 \%)$ & \\
\hline TNM stage & & & & 0.293 \\
\hline II & 35 (51.5\%) & $12(46.2 \%)$ & $23(54.8 \%)$ & \\
\hline III & $14(20.6 \%)$ & $4(15.4 \%)$ & $10(23.8 \%)$ & \\
\hline IV & $19(27.9 \%)$ & $10(38.5 \%)$ & $9(21.4 \%)$ & \\
\hline
\end{tabular}

\section{Generation of mature DCs with cancer-associated antigens}

Approximately $40-60 \mathrm{ml}$ of white cells was obtained from each patient using a blood-cell separator (FreseniusKabi, Germany). The yield of peripheral blood mononuclear cells (PBMCs) ranged from $1 \times 10^{9}-3 \times 10^{9}$ cells. Cells were washed twice with AIM-V cell-culture medium (Gibco, America), transferred into culture flasks, and cultured for 2 hours. Adherent cells were used for induction of DCs by adding 100ng/ml GM-CSF (PeproTech, America) and $100 \mathrm{ng} / \mathrm{ml}$ IL-4 (PeproTech, America) to the AIM-V cell-culture solution. Remaining non-adherent cells from the remainder of the PBMCs were stored at $-80^{\circ} \mathrm{C}$ and thawed for co-cultivation. On day 6, recombinant adenoviruses encoding different TAAs were used to infect DCs (MOI=10). On day 7, IL-1 $\beta$ (25 $\mathrm{ng} / \mathrm{ml}$; Novoprotein, China) and TNF-a (100 ng/ml;
Novoprotein, China) were added into the culture for maturation of DCs.

\section{Preparation of CTLs}

On day 8, TAAs loaded DCs were co-cultured with $\mathrm{T}$ cells at a DC/T-cell ratio of 1:20, stimulated with the CD3 monoclonal antibody (mAb; 50ng/ml; Novoprotein, China), pre-coated onto plastic plates, and amplified by IL-2 (500IU/ml; Quangang Pharmaceutical Co., China). On day 22, cells were infused back into patients via intravenous injection. For each treatment, approximately $3 \times 10^{7}$ cells $/ \mathrm{kg}$ body weight activated $\mathrm{T}$ cells were infused. The viability of cells should be over $95 \%$.

\section{Immunophenotyping of immune cells}

Immune markers CD14, CD80, CD83, CD86 and CD11c for DC cells; CD3 and CD8 for CTL cells; and CD137 and CD69 (24h) for activated T cells were analyzed by flow cytometry on FC500 and Guava EasyCyte $^{\mathrm{TM}}$ flow cytometers (Beckman Coulter, America; Merck Millipore, Germany). In addition, immune indicators were detected using the peripheral blood samples of patients before and after DC-CTLs treatments, and were accessed by the Department of Biotherapy, Eastern Hepatobiliary Surgery Hospital, Second Military Medical University (China). Monoclonal antibodies anti-CD3, -CD4, and -CD8 were used to evaluate $\mathrm{T}$ lymphocyte subgroups, and CD4+/CD25+/ CD127lo/- was used to evaluate Tregs. The proportion of Tregs was calculated by the ratio of CD25hiCD127lo/- cells to CD4+ cells. Flow cytometry data were analyzed by CXP software and GuavaSoft ${ }^{\mathrm{TM}}$ 3.1.1.

\section{Cytokine analysis via intracellular cytokine staining (ICS)}

Samples were divided into one unstimulated group (negative control) and two stimulated groups (positive control and DC-CTLs group). Samples in the stimulated groups were cultured with a 1X cell stimulation cocktail (eBioscience, America) containing phorbol 12-myristate 13-acetate (PMA), ionomycin, brefeldin A and monensin for 4-6 hours. Subsequently, the production of different cytokines, including IFN- $\gamma$, TNF- $\alpha$, and IL-4, was detected using the Intracellular Fixation \&Permeabilization Buffer Set Kit (Beckman Coulter, America).

\section{IFN-Y detection by ELISA, ELISPOT and Cytometric Bead Array (CBA) assay}

To assess the activation of antigen-specific $T$ cells, levels of IFN- $\gamma$ in infused cells were detected by ELISA, human IFN- $\gamma$ ELISPOT kit (Dakewe, Shenzhen, China) and CBA assay (BD, America). CBA is a multiplexed assay that provides the ability to 
quantify multiple proteins within a given sample. The principle of CBA assays is to capture a soluble set of analytes with beads of known size and fluorescence, and sandwich complexes (capture bead + analyte + detection reagent) are formed, which can be measured using flow cytometry.

\section{Quality monitoring}

Infused cells were cultured to detect bacterial endotoxin and mycoplasma levels. In accordance with the Chinese Pharmacopoeia, the level of endotoxin was calculated using the following formula: $\mathrm{L}=\mathrm{K} / \mathrm{M}$. $\mathrm{L}$ is the threshold level of bacterial endotoxin expressed in $\mathrm{EU} / \mathrm{mg}$ or $\mathrm{EU} / \mathrm{u}$. $\mathrm{K}$ is the maximum acceptable endotoxin dosage per kilogram of body weight per hour in the prescribed route of administration in $\mathrm{EU} / \mathrm{kg} / \mathrm{h}$. The default value was $\mathrm{K}=5 \mathrm{EU} / \mathrm{kg} / \mathrm{h} . \mathrm{M}$ is the maximum acceptable dosage in humans per kilogram of body weight per hour. Weight was calculated as $60 \mathrm{~kg}$, and injection time $(\leq$ $1 \mathrm{~h})$ was calculated as $1 \mathrm{~h}$. Our final product volume was $300 \mathrm{ml}$, body weight was calculated as $60 \mathrm{~kg}$, and the time of infusion was $0.5 \mathrm{~h}$. Therefore, the threshold of L was approximately 0.5EU. Microbial detection and Gramstaining were performed by a BacT/ALERT® 3D instrument (Biomerieux, America) and a PREVI® Color Gram staining system (Biomerieux, America). Mycoplasma testing was conducted using an ELISA method.

\section{Detection of biochemical parameters and serological tumor markers}

Levels oftotal bilirubin (TB), alanine transaminase (ALT), aspartate aminotransferase (AST), gamma-glutamyltransferase (GGT), alkaline phosphatase (AKP), serological tumor markers such as alpha fetoprotein (AFP), carcinoembryonic antigen (CEA), and carbohydrate antigen 19-9 (CA199), and the percentage of alpha fetoprotein L3 (AFP-L3\%) were evaluated before and after immunotherapy in patients with HCC. Recommended cutoff-values for diagnostic purposes were 5.1-18.8 $\mu \mathrm{mol} / \mathrm{L}$ for TB, $0-41$ U/L for ALT, 0-37 U/L for AST, 5-61 U/L for GGT, 35-129 U/L for AKP, 0-20 $\mu \mathrm{g} / \mathrm{L}$ for AFP, $0-10 \mu \mathrm{g} / \mathrm{L}$ for CEA, $0-39 \mathrm{U} / \mathrm{ml}$ for CA199 and 0-10\% for AFP-L3\%.

\section{Assessment of quality of life (QoL)}

The EORTC QLQ-C30 questionnaire was designed by the European Organization for Research and Treatment of Cancer (EORTC) to assess specific quality of life issues relevant to cancer patients. The QLQ-C30 (version 3.0) measures health-related QoL from prior week using a global QoL scale, which includes five functional scales, three symptom scales, one quality of life scale, and six other unique items.
Scale scores (range: 0-100) are re-scaled mean scores of their individual component items. Higher global QoL/functional scale scores indicate better QoL, however, higher symptom scale/item scores indicate a higher level of symptomatology. Scores from these scales were assessed using Chi-square tests, with significant results limited to $p$ value $<0.05$. Telephone consultations were conducted for each patient regularly to complete the EORTC QLQ-C30 questionnaire one month after each cycle of DC-CTL treatment $[24,25]$.

\section{Follow-up and survival rates}

OS was defined as the time from the date of enrollment to the date of death due to the tumor or last follow-up. PFS was defined as the date of definitive treatment to the date of tumor recurrence or date of the last follow-up. Patients who were lost to follow-up were considered censored at their date of their last follow-up.

\section{Statistical analysis}

Results were presented as the mean \pm standard deviation (mean $\pm \mathrm{SD}$ ). All data were analyzed by SPSS 22 software (SPSS, Chicago, IL, USA). Differences in demographic and clinical variables of the two groups were tested using the Pearson $\chi^{2}$ test. The Kaplan-Meier method was used to analyze PFS and OS. The log-rank test was used to compare differences in Kaplan-Meier estimates for each group. The Cox proportional hazards regression model was used for univariate analysis. Statistical significance of immune-markers was evaluated by a paired t-test. $P$ values $<0.05$ were considered as statistically significant.

\section{Results}

\section{Patient characteristics}

The present study comprised a retrospective analysis of 68 patients ( 59 males and 9 females) with a median age of 57 (range: 27-80) years. All patients had a confirmed diagnosis of HCC between January 2012 and December 2014 with follow-ups until December 2015 and were divided into two cohorts (a control group and a DC-CTL group). As shown in Table 1, demographic data were comparable between the two groups. The data also indicated that there were no statistically significant differences between the two groups in terms of variables such as, sex, age, TNM stage, and recipient of either radiation therapy or TACE ( $p>0.05)$. Figure 1 showed the detailed schedule from enrollment, treatment, blood collection, cell separation, cell culture, quality monitoring and cell infusion. 


\section{Enrollment}

\section{Inclusion criteria:}

1) The diagnosis was confirmed by pathology of HCC

2) Difficult or refusal to undergo surgery

3) Child-Pugh score $<=9$ (Class A or B)

4) Clinical Oncology Group Eastern (ECOG) score of 0, 1

5) Liver, kidney and blood tests meet the following criteria: WBC $>4 \times 10^{9} / \mathrm{L}$, Neutrophils cells $>1 \times 10^{9} /$ L, Lymphocyte cells $>$ $1 \times 10^{9} / \mathrm{L}$, Hemoglobin $>=100 \mathrm{~g} / \mathrm{L}$ and Platelet $>=80 \times 10^{9} / \mathrm{L}$. The prothrombin time is in a reference range or not extends for more than 3 seconds. Urea nitrogen and serum creatinine do not exceed 1.5 times of the upper limitation.

6) Sign the informed consent form before joining into this study.

\section{Exclusion criteria :}

1) Autoimmune disease or organ transplant history undergoing immunosuppressive therapy

2) Human immunodeficiency virus (HIV) infection, syphilis infection

3) Image evidence of positive or infected blood culture

4) Cell therapy allergies history, cytokines (such as interleukins) allergic history

5) Have uncontrolled heart, lung, kidney, digestion, nerve, metabolism, infectious diseases, mental illness, etc., or other serious diseases

6) Pregnant women

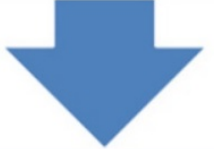

\section{Blood Collection}

Day 0: Approximately $40-60 \mathrm{ml}$ of white cells were obtained from each patient using a blood-cell separator.

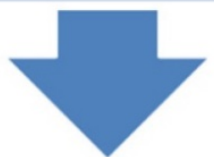

\section{Other Treatment}

\section{TACE Group:}

Day 1,TACE, lipiodol 3-15ml, pirarubicin $40 \mathrm{mg}$, hydroxycamptothecin $10 \mathrm{mg}$, oxaliplatin $100 \mathrm{mg}$.

Radiotherapy Group:

Day 1-5, Cyber knife

\section{Cell Separation}

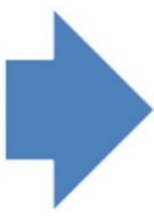

About $1 \times 10^{9}-3 \times 10^{9}$ PBMCs can be obtained by Ficoll cell separation solution.

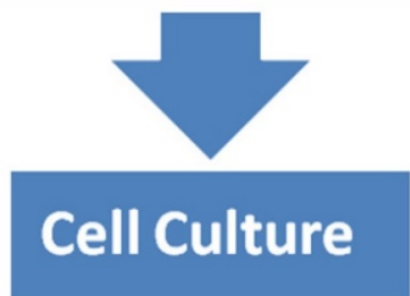

Day 6: recombinant adenoviruses encoding different tumorassociated antigens were used to infect DCs.

Day 7: IL-1 $\beta(25 \mathrm{ng} / \mathrm{ml})$ and TNF- $\alpha(100 \mathrm{ng} / \mathrm{ml}$ were added into the culture for maturation of DCs.

Day 8: DCs were co-cultured with $\mathrm{T}$ cells at a DC/T-cell ratio of $1: 20$. Co-cultured cells were stimulated with the CD3 monoclonal antibody (mAb;50ng/ml), pre-coated onto plastic plates, and amplified by IL-2 (500IU/ml).

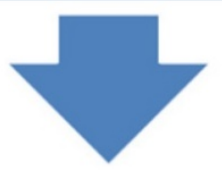

\section{Cell Infusion}

Day 22: After 14 days, cells were infused back into patients via intravenous injection.

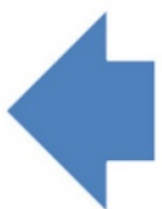

Figure 1. The flow chart of the process of DC-CTLs therapy. The detailed schedule depicted enrollment, treatment, blood collection, cell separation, cell culture, quality monitoring and cell infusion. 

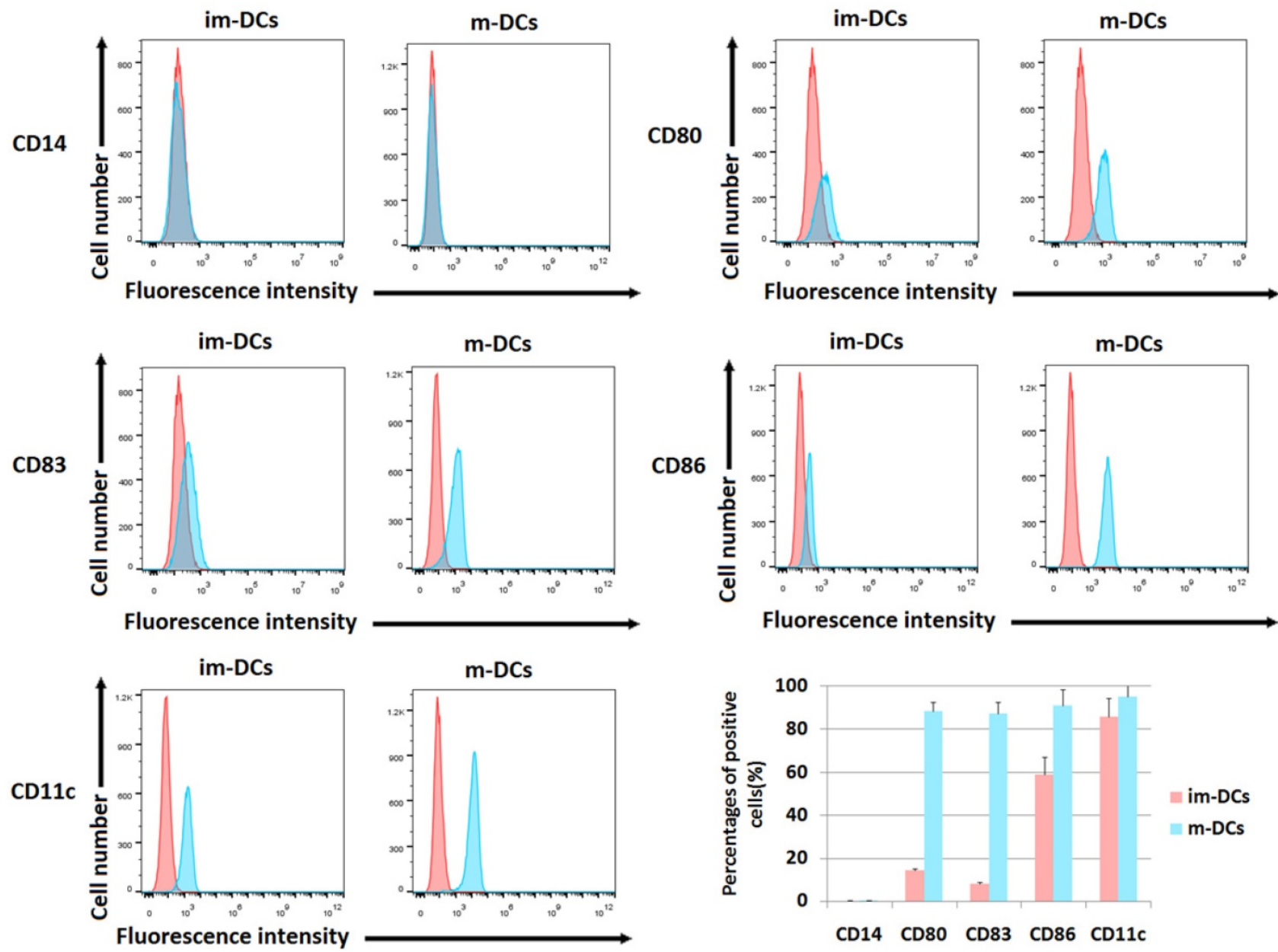

Figure 2. Surface phenotype analysis of DCs. Cells were harvested and processed for staining with the antibody, as indicated. The staining of markers is shown, and the percentage of positive cells is stated $\left({ }^{*} p<0.05\right.$, $* * p<0.005$, ***p $<0.0005$, ****p $\left.<0.00005\right)$. The phenotypic analyses of mature DCs on day 8 were compared with immature $D C s$ on day 4. The biomarkers included CD14, CD80, CD83, CD86, and CD11c. The red peak represents the isotype group. The barplot showed the percentage of cells expressing each biomarker. The proportion of positive cells was calculated on $Y$-axis.

\section{Activities of expanded and activated DCs}

The differences of immune phenotypes between immature DCs and mature DCs, including levels of CD80, CD86, CD83, CD11c and CD14, were analyzed by flow cytometry as shown in Figure 2. Compared with immature DCs (im-DCs), mature DCs (m-DCs) highly expressed various DC markers, including the costimulatory proteins CD80 $(88.55 \% \pm 4.07 \%)$ and CD86 (91.16\% $\pm 7.32 \%)$. Mature DCs also have up-regulated level of the DC activation marker CD83 $(87.40 \% \pm 5.08 \%)$. Additionally, when mature DCs evolved from monocytes, they lost the expression of CD14 (CD14 negative or CD14- DCs). CD11c, a type-I transmembrane protein, is found at a high level on most human DCs $(95.24 \% \pm 4.97 \%)$. In Figure 2, the flow cytometric dot plots showed the results from one representative experiment, and the barplot described the statistical analysis of the percentages of positive cells. DCs exhibited high-level expression of CD80, CD86, CD83 and CD11c on day 8, which confirmed the maturation of DCs after cultivation.

\section{Activities of expanded and activated DC-CTLs}

We consistently tested the quality of the $\mathrm{T}$ cells by detecting the percentage of the activation markers CD69, CD28, and CD137 and the percentage of CD3+CD8+ CTLs. Among the cultivated CD3+ T cells, the population of activated CD69+ after $24 \mathrm{~h}$ and CD28+ and CD137+ $\mathrm{T}$ cells after day 14 reached $91.16 \% \pm 1.03 \%, 93.00 \% \pm 5.49 \%$, and $23.80 \% \pm 4.57 \%$, and CD3+CD8+ CTLs reached $87.71 \% \pm 2.32 \%$, respectively, which were higher than those in CIKs (CD69+: $31.23 \% \pm 3.15 \%$; CD28+: $51.87 \% \pm 5.53 \%$; CD137+: $2.19 \% \pm 1.31 \%$; CD8+: $60.4 \% \pm 4.86 \%)$ and DC-CTLs without TAAs stimulation (CD69+: $54.3 \% \pm 2.87 \%$; CD28+: $62.13 \% \pm 7.36 \%$ ； CD137+: $6.07 \% \pm 0.23 \%$; CD8+: $73.83 \% \pm 4.71 \%$ ).

Production of intracellular cytokines was measured by ICS. IFN- $\gamma$ and TNF- $\alpha$ exhibited higher levels during in vitro cultivation, and the proportion of T cells expressing IFN- $\gamma$ and TNF- $\alpha$ was $17 \%$ and 
$19.3 \%$, respectively, compared to unstimulated T cells and Ad-Blank DC-CTLs stimulated with a cell stimulation cocktail (Figure 3). The percentage of $\mathrm{T}$ cells that secreted IL-4, which generally decreases the production of IFN- $\gamma$, was less than $1 \%$,

Furthermore, antigen-specific $\mathrm{T}$ cell responses were measured by ELISA and CBA assay. The production of IFN- $\gamma$ reached $6756.53 \pm 145.96 \mathrm{pg} / \mathrm{ml}$ in re-fused cells compared with $1440.97 \pm 11.89 \mathrm{pg} / \mathrm{ml}$ in unstimulated controls (estimated via ELISA). In addition, the CBA assay showed that levels of IFN- $\gamma$ were significantly higher in infused cells $(7308.53 \pm 527.60 \mathrm{pg} / \mathrm{ml})$ than in unstimulated controls $(1145.94 \pm 179.16 \mathrm{pg} / \mathrm{ml})$. The Elispot experiment showed that the DC-CTL group exhibited an average of 142 spots which highly increased spot numbers compared to the negative control with very few spots or none at all.

\section{Quality monitoring}

Cells were cultured for the detection of bacterial endotoxin and mycoplasma levels. All cultured samples met the release criteria for infusion.

\section{Analysis of quality of life}

A pre- and post-treatment evaluation of the health-related quality of life in patients with HCC was conducted. During analysis of the EORTC QLQ-C30 questionnaire for the control group, patients who received conventional therapy had significantly higher scores for nausea and emesis, appetite loss, and diarrhea than pretreatment patients $(p<0.05)$. Strikingly, the global health/quality of life score improved significantly in patients who underwent DC-CTLs therapy. Collectively, there was a statistically significant difference in life quality between the two groups $(p=0.017)$, and the physical-functioning (PF) scale showed a strong improvement during the course of therapy $(p=0.005)$. Fatigue, nausea and emesis, dyspnea, insomnia, constipation, and diarrhea decreased slightly during the course of immunotherapy but not significantly (Figure 4). The increased scores in the function scale/overall QoL and the decreased scores in the symptom scales showed an improved quality of life for patients with HCC who underwent DC-CTLs treatment.
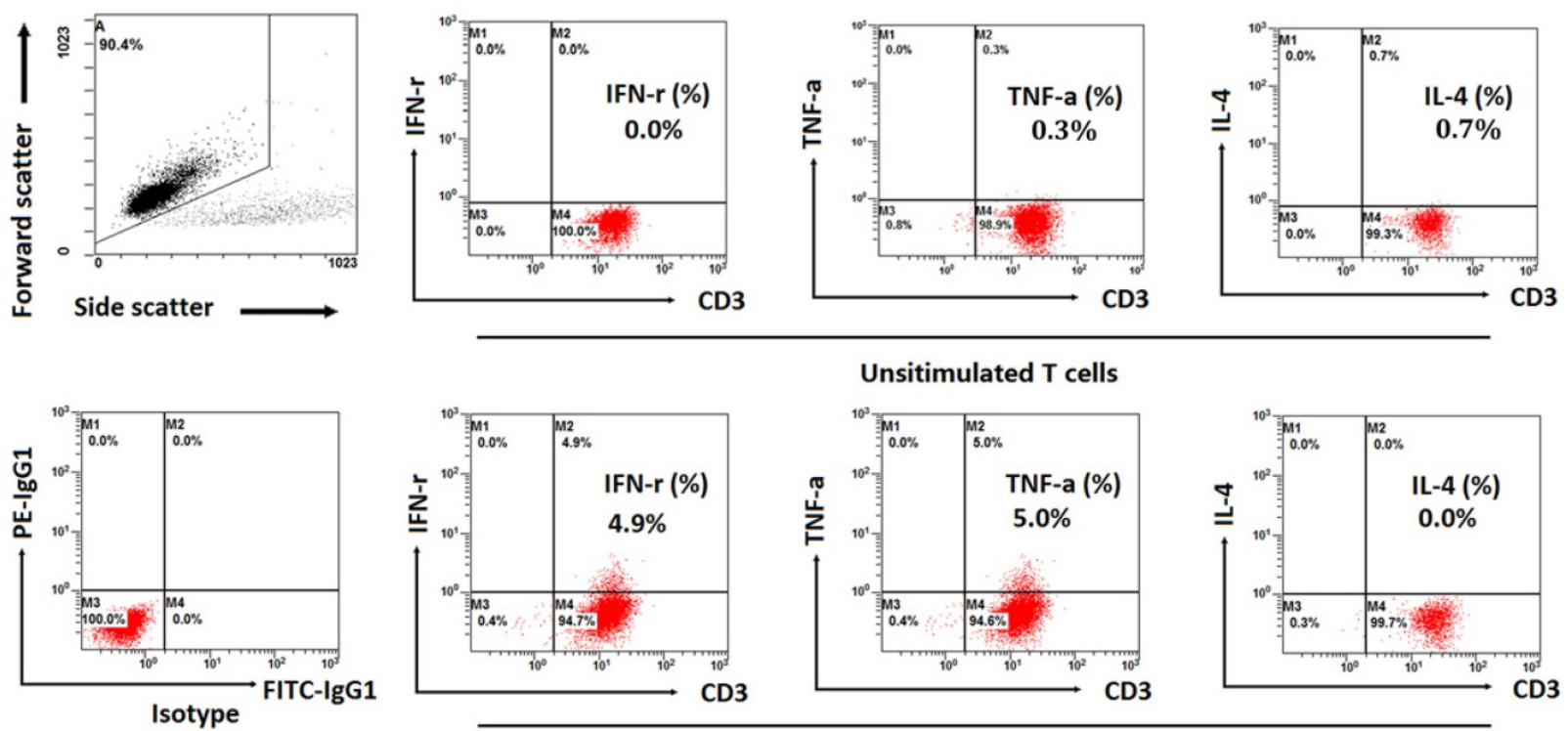

Ad-Blank Group / Cell stimulation cocktail
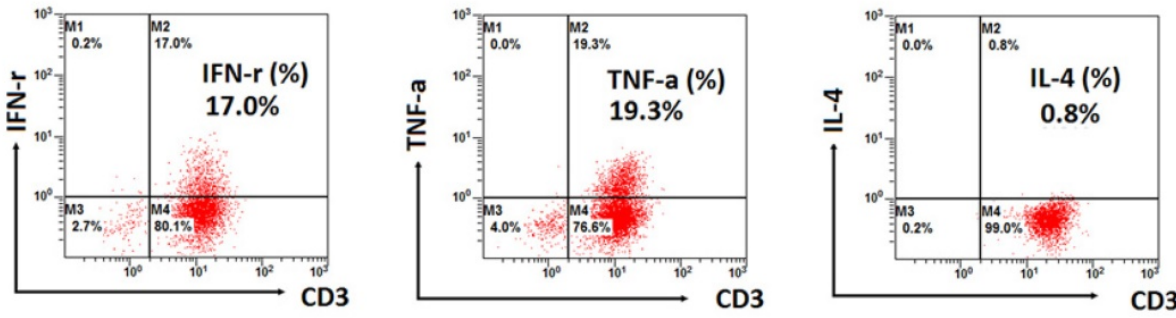

DC-CTLs

Figure 3. Detection of intracellular IFN- $y$, TNF- $\alpha$, IL-4 and IFN-y concentrations in the supernatant. Dot plots show the proportion of T cells expressing IFN- $y$, TNF- $\alpha$, and IL-4. The top left plot represents the gating strategy. The bottom left plot represents the isotype group. The $2^{\text {nd }}$ to $4^{\text {th }}$ plots on the top represent unstimulated T cells, the $2^{\text {nd }}$ to $4^{\text {th }}$ plots in the middle represent the Ad-Blank group (the recombinant non-proliferative adenovirus without any expression cassettes of tumor-associated antigens) stimulated with the cell stimulation cocktail, and the $2^{\text {nd }}$ to $4^{\text {th }}$ plots on the bottom represent the production of cytokines by DC-induced antigen-specific CTL cells. 

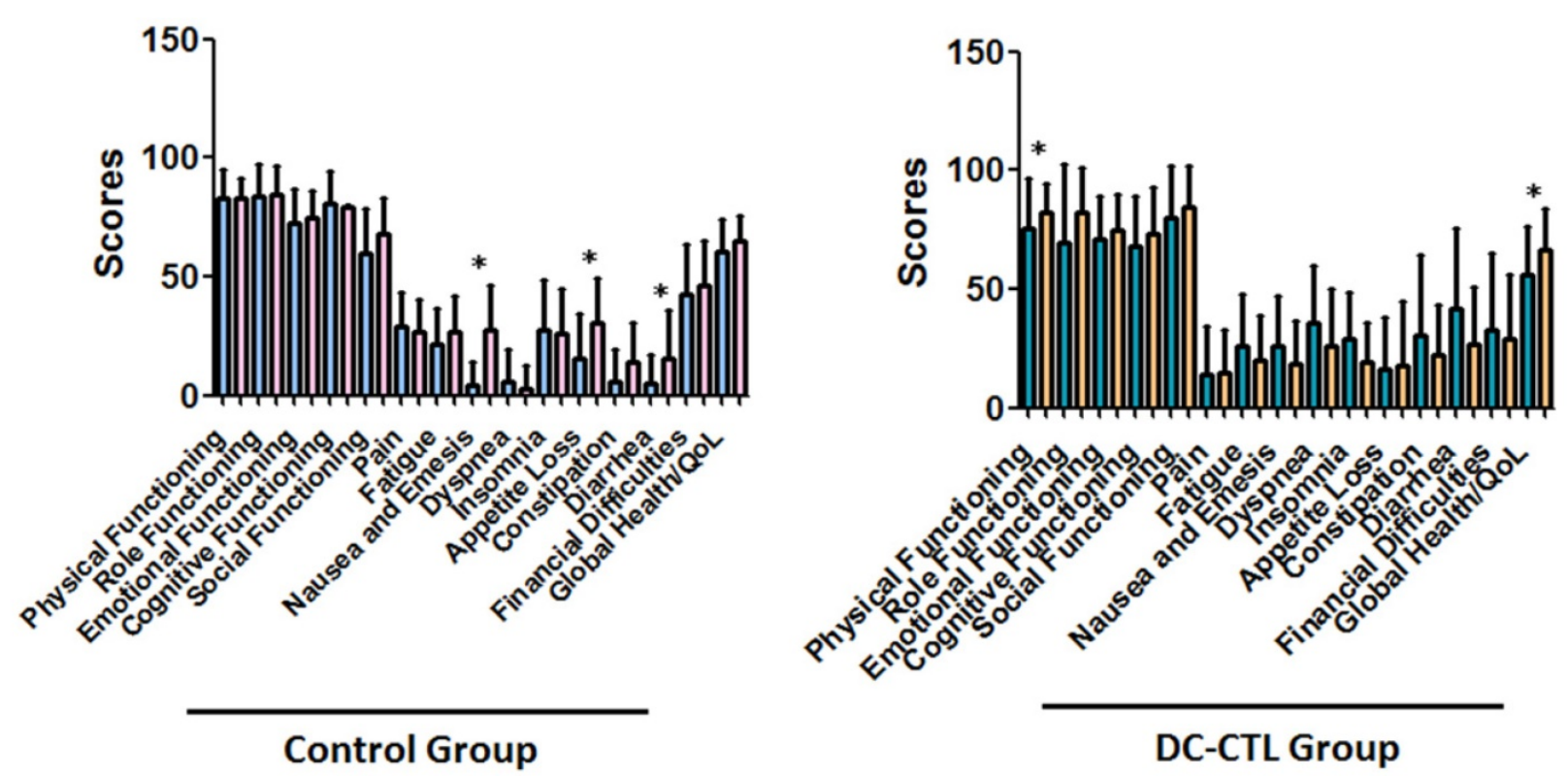

Control_pre-therapy

Control_post-treatment

DC-CTL_pre-therapy

DC-CTL_post-treatment

Figure 4. Change in quality of life. The bar plot describes various scales for all the tumor patients measured at two visit times. The black bar represents the pre-immunotherapy visit, and the white bar indicates the last follow-up time after DC-CTL treatment. The X-axis represents the key scales of QLQ-C30, including, physical functioning (PF), role functioning (RF), emotional functioning (EF), cognitive functioning (CF), social functioning (SF), pain (PA), fatigue (FA), nausea and emesis $(N V)$, dyspnea (DY), insomnia (SL), appetite loss (AP), constipation (CO), diarrhea (DI), financial difficulties (FD), and quality of life (QoL). The scale score was calculated and indicated on $Y$-axis. *Statistically significant differences $\left({ }^{*} p<=0.05\right.$, $\left.{ }^{*} p<=0.005\right)$

\section{Change of serological index}

Considering the possible presence of clinical heterogeneity among patients, we employed Chi-square tests to evaluate clinical response. During analysis of the serological index of the DC-CTL group, we observed that the mean levels of AFP, AFP-L3, ALT, and CA199 were significantly lower after DC-CTL treatment $(p=0.0437, p=0.0471, p=0.0037$, $\mathrm{p}=0.0262$, respectively) than the mean levels in pre-therapy patients. Patients who underwent DC-CTL therapy had lower average serum levels of AST and TB, although these differences were not highly significant $(p>0.05)$. Nevertheless, there were no significant differences in these serological indexes before and after treatment in the control group (Figure 5a).

\section{Treg cells decreased after DC-CTL immunotherapy}

Subsequently, we investigated the changes of immune indicators, including CD3, CD4, CD8, and Treg, pre- and post-DC-CTL treatment. The 8 of 11 patients who received DC-CTL therapy showed a lower percentage of Tregs $(<10 \%)$, and Tregs $(\%)$ in 26 of 42 patients decreased after treatment. The proportion of Treg cells reduced significantly in patients undergoing either radiotherapy or TACE $(p=0.001422)$. Moreover, percentages of $C D 3+C D 4+T$ lymphocytes decreased significantly $(\mathrm{p}<0.0001)$, and the number of $\mathrm{CD} 3+\mathrm{CD} 8+\mathrm{T}$ lymphocytes in the peripheral blood tended to increase $(p<0.0001)$. In comparison, there were no statistically different changes in CD3+ cells (Figure 5b).

\section{Overall survival and progression-free survival}

Clinical factors were further evaluated by Cox proportional hazards regression analysis. Notably, DC-CTLs treatment showed a significant association with PFS and OS in the univariate analysis, although sex, age, TACE, radiotherapy, and TNM stages were not independent prognostic factors for OS and PFS (Table 2).

We subsequently investigated whether this observation was related to DC-CTL treatment. Patients had periodic follow-up until December 2015. The median OS and PFS were 8.2 months and 4.3 months, respectively, for the control group and 12.8 months and 9 months, respectively, for the DC-CTL treatment group. Patients treated with DC-CTLs therapy showed a statistically significant PFS and OS curve compared with the control group (OS: $p=0.016$; PFS: $p<0.0001$; Figure 6a).

In addition, adjunctive therapies (TACE therapy or radiotherapy) could be associated with the prognosis of patients with HCC, while they may not be regarded as independent prognostic factors in Cox proportional hazards regression analysis. Therefore, 
we further compared OS and PFS in the TACE and radiotherapy subgroup. In a follow-up comparison of 1-year for OS and PFS between the TACE-alone and TACE+DC-CTL groups, OS increased from $42.9 \%$ to $64.5 \%$, and PFS rates increased from $23.8 \%$ to $38.7 \%$. Similarly, one-year OS rates increased from $20 \%$ to $45.5 \%$ in the radiotherapy + DC-CTL group compared with the radiotherapy-alone group. The median OS and PFS were 4.93 months for patients undergoing radiotherapy alone and 11.47 months and 7.67 months for those undergoing radiotherapy along with DC-CTL treatment (Figure 6b). Additionally, OS and PFS were 9.33 months and 3.57 months, respectively, for the TACE-alone group and 12.9 months and 9.2 months, respectively, for the DC-CTL treatment group. Patients in the DC-CTL group showed a statistically significant PFS and OS curve, respectively (PFS: $\mathrm{p}=0.017, \mathrm{p}=0.002$; OS: $\mathrm{p}=0.042, \mathrm{p}=0.035$; Figure $6 c)$.
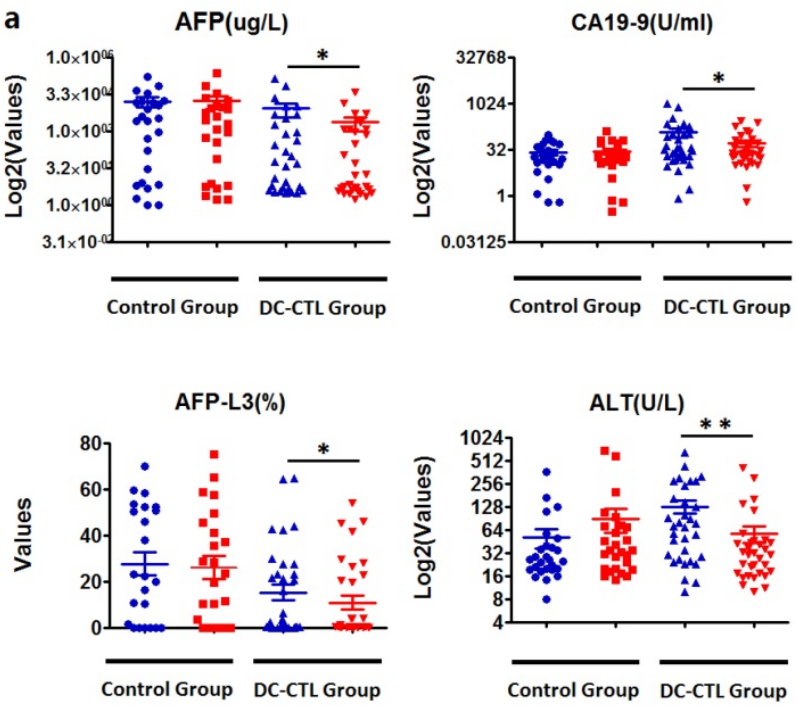

- Control_pre-therapy $/$ Control_post-treatment A DC-CTL_pre-therapy V DC-CTL_post-treatment

\section{Safety}

Side effects were recorded in 68 cases. There were no severe or unusual side effects, except for temporary fever. In total, 27 of 68 cases developed a fever during immunotherapy, and body temperature ranged from $37.5-40^{\circ} \mathrm{C}$. Most of these patients recovered without any treatment. No side effects on the liver and kidney were found.

\section{Discussion}

Thus far, a number of agencies have carried out clinical trials and made progress in the use of DC-CTLs therapy in the treatment of metastatic renal-cell carcinoma, gastric cancer, and other malignancies [26]. Previous research reported that DC-based antigen-specific immunotherapy still faces some obstacles, including inefficient cultivation of DCs, TAAs alteration, and the presence of extrinsic regulators, including Tregs [14, 27]. Our study showed that a cocktail of TAAs-loaded DCs could enhance the response of CTLs against HCC.

b
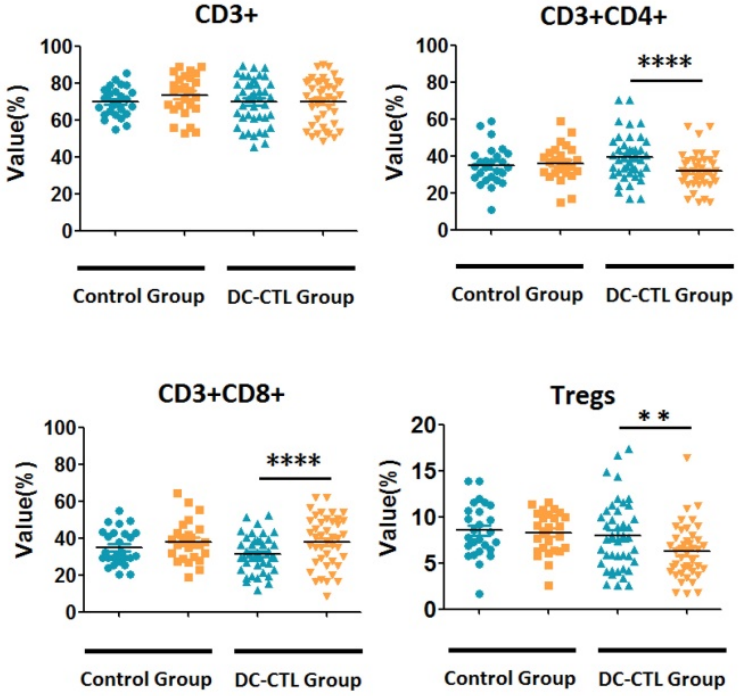

Control_pre-therapy " Control_post-treatment 4 DC-CTL_pre-therapy $\quad$ DC-CTL_post-treatment

Figure 5. Change in clinical and immune indicators a. The boxplot describes various clinical indicators for all patients, before and after DC-CTL treatment. The $X$-axis represents crucial clinical indicators, including ALT, AFP, CA19-9, and the percentage of alpha-fetoprotein L3 (AFP-L3(\%)). These values were calculated and indicated on the $\mathrm{Y}$-axis $\left({ }^{*} \mathrm{p}<0.05\right.$, $\left.{ }^{*} \mathrm{p}<0.005\right)$. b. Changes in immune indicators, including CD3+, CD3+CD4+, CD3+CD8+, and Tregs, before and after DC-CTL treatment compared with patients in the control group $\left(* \mathrm{p}<0.05, * * \mathrm{p}<0.005,{ }^{*} * \mathrm{p}<0.0005\right)$.

Table 2. Univariate analysis of OS and PFS in patients

\begin{tabular}{llll}
\hline Variables & OS & \multicolumn{2}{l}{ PFS } \\
\cline { 2 - 4 } & HR(95\% Cl) & $\mathrm{P}(95 \% \mathrm{Cl})$ \\
\hline Sex (male vs. female) & $0.482(0.194-1.215)$ & 0.122 & $0.535(0.212-1.351)$ \\
Age (<=57 vs. > 57) & $0.709(0.409-1.230)$ & 0.221 & $1.206(0.693-2.100)$ \\
TACE therapy (no vs. yes) & $1.514(0.463-4.949)$ & 0.492 & $0.786(0.244-2.533)$ \\
Radiotherapy (no vs. yes) & $0.703(0.398-1.242)$ & 0.225 & $0.723(0.401-1.304)$ \\
Surgery (no vs. yes) & $1.759(0.901-3.435)$ & 0.098 & $1.074(0.539-2.139)$ \\
DC-CTL therapy (no vs. yes) & $1.928(1.117-3.327)$ & 0.018 & $2.671(1.536-4.645)$ \\
T (2 vs. 3,4) & $0.505(0.226-1.127)$ & 0.095 & $0.811(0.363-1.812)$ \\
N (0 vs. 1,2) & $1.308(0.737-2.321)$ & 0.358 & $1.063(0.593-1.905)$ \\
TNM Stage (IIA vs. IIB, IIC, III, IV) & $0.578(0.229-1.460)$ & 0.246 & 0.001 \\
\hline
\end{tabular}

Abbreviation: $\mathrm{CI}$ confidence interval. 

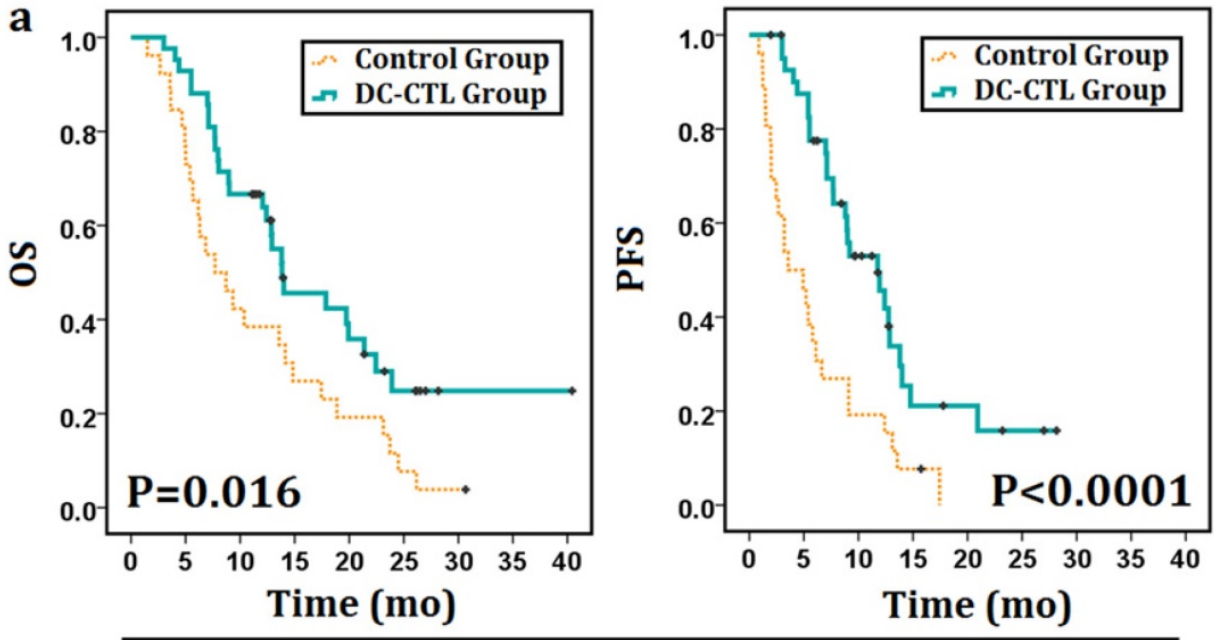

Radiotherapy + TACE therapy (DC-CTL, N=42; Control, $\mathrm{N}=26$ )
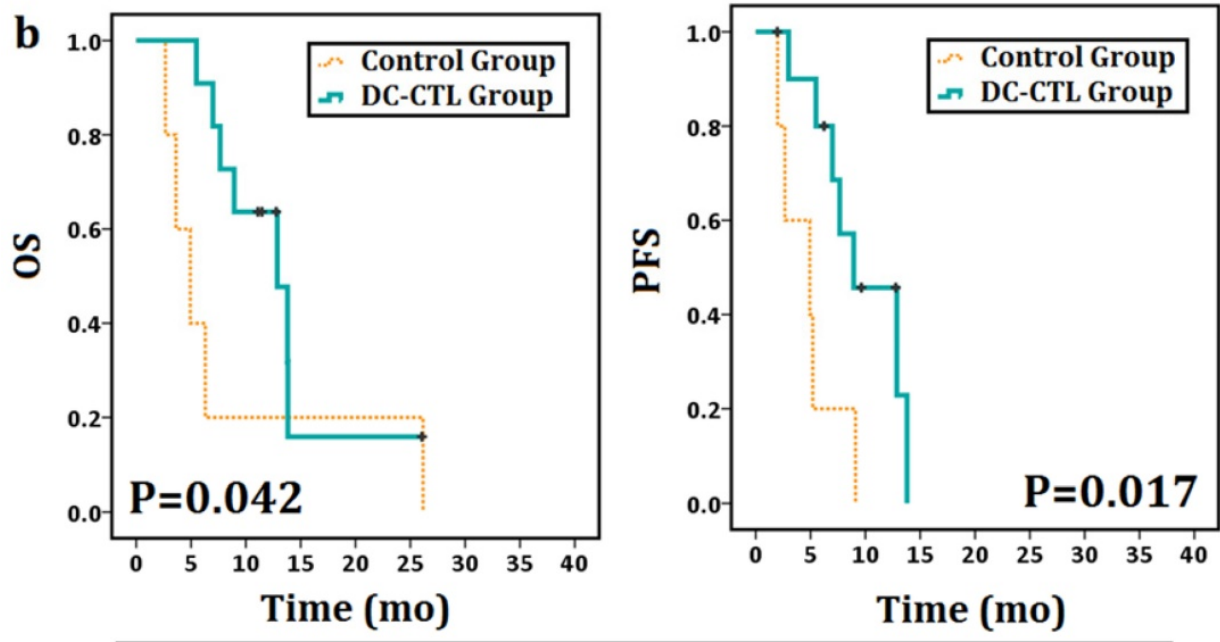

Radiotherapy (DC-CTL, N=11; Control, N=5)
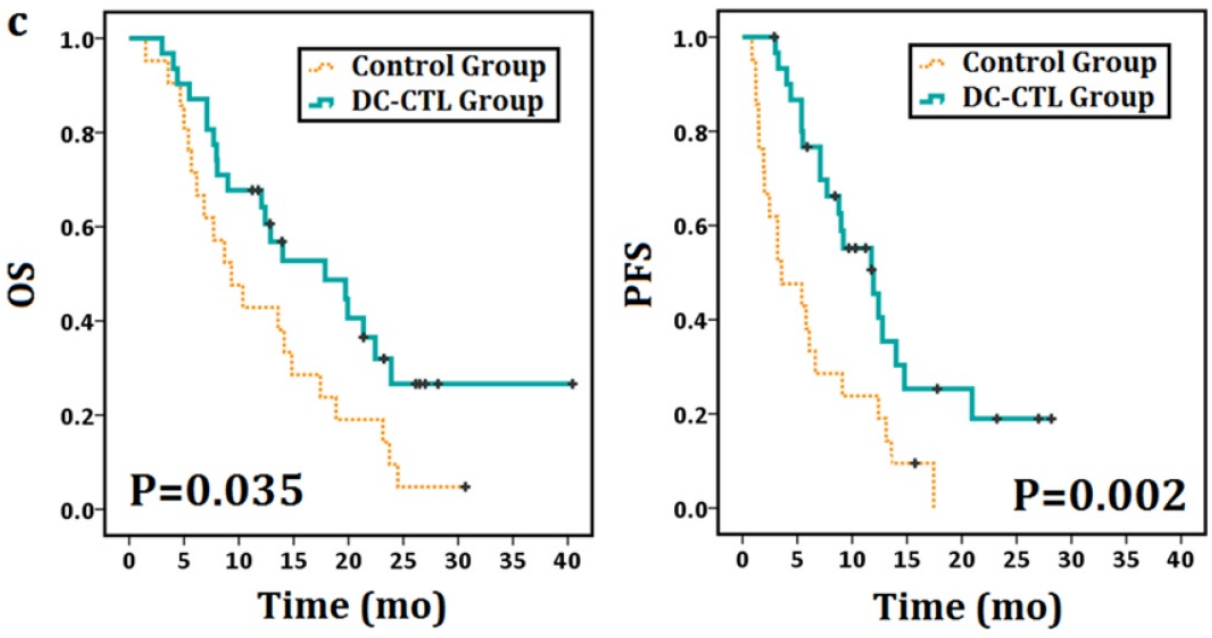

TACE therapy (DC-CTL, $\mathrm{N}=31$; Control, $\mathrm{N}=21$ )

Figure 6. Survival analyses of patients with HCC Survival analyses were performed to estimate the prognosis of patients with HCC. The Kaplan-Meier method was used to compare survival rates between patients undergoing DC-CTL therapy combined with adjuvant strategies (the DC-CTL group) and those undergoing radiotherapy or TACE therapy alone (the control group). *Statistically significant differences $(* p<0.05, * * p<0.005)$. a. OS curves and PFS curves for all patients. b. OS curves and PFS curves for the radiotherapy subgroup. c. OS curves and PFS curves for the TACE therapy subgroup. 
In this study, we utilized automatic blood sampling via a blood-cell separator to improve the harvesting of DCs. This method is typically used in treatment of leukemia [28, 29], but it is less often reported in immunotherapy. According to the parameter setting, white cells are collected within several circuits, while the remainder of the blood components is returned to the patient via a returning chamber. In total, approximately $1 \times 10^{9}-3 \times 10^{9}$ PBMCs can be obtained by Ficoll cell separation solution. Therefore, the number of DCs obtained from blood samples was significantly higher than those obtained by venipunctures. At present, we can collect $1 \times 10^{9}-3 \times 10^{9}$ PBMC cells per $40-60 \mathrm{ml}$ of white blood cells via the blood cell separator as well as acquire approximately $1 \times 10^{8}$ DCs per $40-60 \mathrm{ml}$ of white cells in vitro, which enables us to harvest sufficient DCs for cultivation. In addition, we compared DC markers between healthy donors and patients. Levels of maturation achieved by DCs were lower for patients than for donors. We determined that it was better to compare the change of DCs in the same patient because patients' DCs could not completely recover after in vitro stimulation.

Cytokines frequently play an important role in immunity, are involved in tumor progression, and provide crucial information regarding activated DC-CTLs. Several studies have suggested that the expression of IFN- $\gamma$ and TNF- $\alpha$ in T cells is associated with the response of tumor-specific $\mathrm{T}$ cells, and this produces significant anti-tumor effects by inhibiting tumor-cell proliferation and promoting tumor cell apoptosis. Production of TNF- $\alpha$ and IFN- $\gamma$ exert a strong synergistic boost to antigen-specific immune responses during DC-CTL immunotherapy [30-32]. Others indicated that the presence of IL-4 could markedly impair CD8 $+\mathrm{T}$ cell expansion and additionally inhibit IL-12 production by DCs and IFN-y secretion [33-35]. Herein, we demonstrated that our approach increased expression levels of IFN- $\gamma$ and TNF- $\alpha$, indicating that antigen-specific $T$ cells were activated.

Studies have confirmed the benefits and the safety aspects of DC-CTLs therapy for patients with HCC. We tested the quality of the infused cells and used a combination of indicators, including immune indicators, serological tumor markers, QoL, OS, PFS, and observed side effects, for an in-depth assessment of the treatment. We greatly decreased the proportion of Tregs, which contain potent anti-tumor immune-suppressive function in the immune system $[36,37]$. A high level of Tregs is a prognostic factor, and it is regarded as an adverse factor in patients with malignant tumors. Compared with the Tregs proportion in control group, a higher percentage of
Tregs was found in patients with HCC, possibly due to immune-dysfunction prior to treatment. Notably, in our study, a robust immune response was observed in patients with a reduced proportion of Tregs and CD4+ $\mathrm{T}$ cells as well as an increased proportion of CD8+ T cells. A series of serum biomarkers, such as AFP, AFP-L3, ALT, and CA199, are routinely tested in patients with HCC to reflect the clinical response after DC-CTLs therapy. AFP-L3 is calculated as the proportion of AFP-L3 over total AFP levels, which can be used with AFP as biomarkers to indicate HCC [38]. Previous studies have suggested that high serum AFP-L3\% levels indicated a poor prognosis for HCC patients [39, 40]. Similarly, the serum level of CA19-9 is also found to be elevated in HCC patients, and it is considered as a predictor of survival for HCC [41]. In addition, a high serum level of ALT is commonly reported to indicate the status of liver injury [42]. Therefore, these clinical indexes may have significant prognostic value in HCC patients with low serum concentrations. A decrease of these clinical indicators simultaneously after DC-CTL treatment may reflect a therapeutic effect of this treatment on HCC. The side effects and toxicity of DC-CTLs therapy were mild and easily controllable. The response of DC-CTLs immunotherapy is well tolerated by patients who were unable or unwilling to experience the adverse side effects of conventional therapies. The results of DC-CTL treatment showed that the treatment significantly improved the global health of patients (QoL score, p-value<0.05).

In this study, we measured long-term effects of DC-CTLs therapy on 68 patients. However, similar studies are needed in the future with a larger number of patients suffering from different types of tumors to further investigate the clinical response of this approach. We have developed an immunotherapeutic strategy for the treatment of patients with HCC, but further optimization strategies are still required. Previous report has elaborated on neo-antigens in cancer immunotherapy and personalized antigens for cancer treatment [43]. Therefore, at present, further optimization of protocols for cell isolation and standardization of the cocktail of TAAs is being attempted. A novel cocktail of TAAs, such as ERBB1, ERBB2, ERBB3, ERBB4, MAGE-A1, MAGE-A3, GPC3 and MUC1, as well as several personalized antigens for patients, such as the use of AFP or CEA antigens for therapy in patients with AFP+ or CEA+, are being investigated in our further studies to improve the anti-tumor effects of DC-CTLs immunotherapy and prolong survival of patients.

In summary, we improved the existing protocol for harvesting high-quality sufficient DCs, and we investigated the effect of DC-CTLs therapy on 
patients with HCC. Our results showed that it significantly reduced the proportion of Tregs as well as several specific clinical indexes, including AFP, AFP-L3, ALT and CA19-9. The DC-CTLs treatment may preserve or improve the quality of life in patients who have invasive cancers. These findings indicate the role of the DC-CTLs therapy in patients with HCC.

\section{Abbreviations}

AFP: Alpha fetoprotein; AKP: Alkaline phosphatase; ALT: Alanine transaminase; AST: Aspartate aminotransferase; CA199: Carbohydrate antigen 19-9; CBA: Cytometric bead array; CEA: Carcinoembryonic antigen; DC-CTLs: Dendritic cell-cytotoxic T lymphocytes; EORTC: The European Organization for Research and Treatment of Cancer; GGT: Gamma-glutamyl transferase; HAL: Hepatic artery ligation; HCC: Hepatocellular carcinoma; hTERT: Human telomerase reverse-transcriptase; ICS: Intracellular cytokine staining; OLT: Orthotopic liver transplantation; OS: Overall survival; PBMCs: Peripheral blood mononuclear cells; PEI: Percutaneous intra-tumor ethanol injection; PF: Physical-functioning; PFS: Progression-free survival; PLC: Primary liver cancers; PMA: Phorbol 12-myristate 13-acetate; QoL: Quality of life; TAAs: Tumor-associated antigens; TACE: Transarterial chemoembolization; TB: Total bilirubin; Tregs: Regulatory T cells.

\section{Supplementary Material}

Supplementary Table S1.

http://www.jcancer.org/v09p0275s1.pdf

\section{Acknowledgments}

This work was supported by the National Natural Science Foundation of China (grant numbers 81672997, 31601075, 81573023 and 81301307), and the Capacity Building Project of Shanghai Engineering Research Center (16DZ2281000).

\section{Compliance with Ethical Standards}

The trial was approved by the Committee on Medical Ethics of Eastern Hepatobiliary Surgical Hospital. All patients in our trial have signed informed consents.

\section{Competing Interests}

The authors have declared that no competing interest exists.

\section{References}

1. Buonaguro L, Petrizzo A, Tagliamonte $\mathrm{M}$, et al. Challenges in cancer vaccine development for hepatocellular carcinoma. J Hepatol. 2013; 59(4):897-903.
2. Wu MC. Clinical research advances in primary liver cancer. World J Gastroenterol. 1998; 4(6):471-474

3. Doyle A, Marsh P, Gill R, et al. Sorafenib in the treatment of hepatocellular carcinoma: a multi-centre real-world study. Scand J Gastroenterol. 2016; 51:979-985.

4. Palmer DH, Midgley RS, Mirza N, et al. A phase II study of adoptive immunotherapy using dendritic cells pulsed with tumor lysate in patients with hepatocellular carcinoma. Hepatology. 2009; 49(1):124-132.

5. El Ansary M, Mogawer S, Elhamid SA, et al. Immunotherapy by autologous dendritic cell vaccine in patients with advanced HCC. J Cancer Res Clin Oncol. 2013; 139(1):39-48

6. Cui Y, Yang X, Zhu W, et al. Immune response, clinical outcome and safety of dendritic cell vaccine in combination with cytokine-induced killer cell therapy in cancer patients. Oncol Lett. 2013; 6(2):537-541.

7. Choi D, Kim TG, Sung YC. The past, present, and future of adoptive T cell therapy. Immune Netw. 2012; 12(4):139-147.

8. Bray SM, Vujanovic L, Butterfield LH. Dendritic cell-based vaccines positively impact natural killer and regulatory $\mathrm{T}$ cells in hepatocellular carcinoma patients. Clin Dev Immunol. 2011; 2011:249281.

9. Pardee $\mathrm{AD}$, Yano $\mathrm{H}$, Weinstein AM, et al. Route of antigen delivery impacts the immunostimulatory activity of dendritic cell-based vaccines for hepatocellular carcinoma. J Immunother Cancer. 2015; 3:32.

10. Zhou J, Ma P, Li J, et al. Improvement of the cytotoxic T lymphocyte response against hepatocellular carcinoma by transduction of cancer cells with an adeno-associated virus carrying the interferon-gamma gene. Mol Med Rep. 2016; 13(4):3197-3205

11. O'Beirne J, Farzaneh F, Harrison PM. Generation of functional CD8+ T cells by human dendritic cells expressing glypican-3 epitopes. J Exp Clin Cancer Res. 2010; 29:48.

12. Liu X, Li J, Liu Y, et al. Calreticulin acts as an adjuvant to promote dendritic cell maturation and enhances antigen-specific cytotoxic $\mathrm{T}$ lymphocyte responses against non-small cell lung cancer cells. Cell Immunol. 2016; 300:46-53

13. Sui CG, Wu D, Meng FD, et al. Anti-prostate cancer effects of CTL cell induction in vitro by recombinant adenovirus mediated PSMA/4-1BBL dendritic cells: an immunotherapy study. Genet Mol Res. 2015; 14(2):7208-7217.

14. Wang $X$, Zhang FC, Zhao HY, et al. Human IP10-scFv and DC-induced CTL synergistically inhibit the growth of glioma in a xenograft model. Tumour Biol. 2014; 35(8):7781-7791.

15. Zhang Y, Li Q Liu N, et al. Detection of MAGE-1, MAGE-3 and AFP mRNA as multimarker by real-time quantitative PCR assay: a possible predictor of hematogenous micrometastasis of hepatocellular carcinoma. Hepatogastroenterology. 2008; 55(88): 2200-2206.

16. Dong J, Wang L, Tian YP, et al. hTERT single nucleotide polymorphism is associated with increased risks of hepatocellular carcinoma and tumor metastasis. Nan Fang Yi Ke Da Xue Xue Bao. 2011; 31(1):49-52.

17. Cioca A, Cimpean A, Ceausu R, et al. Crosstalk between EGFR and p53 in hepatocellular carcinoma. Asian Pac J Cancer Prev. 2014; 15(19):8069-8073.

18. Or YY, Chow AK, Ng L, et al. Survivin depletion inhibits tumor growth and enhances chemosensitivity in hepatocellular carcinoma. Mol Med Rep. 2014; 10(4):2025-2030.

19. Cicinnati VR, Zhang $\mathrm{X}, \mathrm{Yu} \mathrm{Z}$, et al. Increased frequencies of CD8+ T lymphocytes recognizing wild-type p53-derived epitopes in peripheral blood correlate with presence of epitope loss tumor variants in patients with hepatocellular carcinoma. Int J Cancer. 2006; 119(12):2851-2860.

20. Mizukoshi E, Nakagawa $H$, Kitahara $M$, et al. Immunological features of $T$ cells induced by human telomerase reverse transcriptase-derived peptides in patients with hepatocellular carcinoma. Cancer Lett. 2015; 364(2):98-105.

21. Kollgaard T, Ugurel-Becker S, Idorn M, et al. Pre-Vaccination Frequencies of Th17 Cells Correlate with Vaccine-Induced T-Cell Responses to Survivin-Derived Peptide Epitopes. PLoS One. 2015; 10(7):e0131934.

22. Wang $\mathrm{Y}, \mathrm{Xu} \mathrm{Z}, \mathrm{Zhou} \mathrm{F}$, et al. The combination of dendritic cells-cytotoxic $\mathrm{T}$ lymphocytes/cytokine-induced killer (DC-CTL/CIK) therapy exerts immune and clinical responses in patients with malignant tumors. Exp Hematol Oncol. 2015; 4:32.

23. Chen J, Su C, Lu Q, et al. Generation of adenovirus-mediated anti-CD20 antibody and its effect on B-cell deletion in mice and nonhuman primate cynomolgus monkey. Mol Cancer Ther. 2008; 7(6):1562-1568.

24. Aaronson NK, Ahmedzai S, Bergman B, et al. The European Organization for Research and Treatment of Cancer QLQ-C30: a quality-of-life instrument for use in international clinical trials in oncology. J Natl Cancer Inst. 1993; 85(5):365-376.

25. Greimel ER, Kuljanic Vlasic K, Waldenstrom AC, et al. The European Organization for Research and Treatment of Cancer (EORTC) Quality-of-Life questionnaire cervical cancer module: EORTC QLQ-CX24 Cancer. 2006. 107(8):1812-1822

26. Tada F, Abe M, Hirooka M, et al. Phase I/II study of immunotherapy using tumor antigen-pulsed dendritic cells in patients with hepatocellular carcinoma. Int J Oncol. 2012; 41(5):1601-1609.

27. Ahmed MS, Bae YS. Dendritic cell-based therapeutic cancer vaccines: past, present and future. Clin Exp Vaccine Res. 2014; 3(2):113-116.

28. Gonye $S$, Horvath $Z$. Experiences with automatic blood cell count devices with special reference to the hematologic examination of bovine leukosis. Arch Exp Veterinarmed. $1971 ; 25(4): 765-768$ 
29. Komatsu F, Ishida Y. Efficient collection of peripheral blood stem cells using the Fresenius AS104 in chronic myelocytic leukemia patients with very high numbers of platelets. J Hematother. 1997; 6(2):133-136.

30. Schoenborn JR, Wilson CB. Regulation of interferon-gamma during innate and adaptive immune responses. Adv Immunol. 2007; 96:41-101.

31. Ghanekar SA, Nomura LE, Suni MA, et al. Gamma interferon expression in CD8(+) $\mathrm{T}$ cells is a marker for circulating cytotoxic $\mathrm{T}$ lymphocytes that recognize an HLA A2-restricted epitope of human cytomegalovirus phosphoprotein pp65. Clin Diagn Lab Immunol. 2001; 8(3):628-631.

32. Liu $\mathrm{F}, \mathrm{Hu} \mathrm{X}$, Zimmerman $\mathrm{M}$, et al. TNFalpha cooperates with IFN-gamma to repress $\mathrm{Bcl}-\mathrm{xL}$ expression to sensitize metastatic colon carcinoma cells to TRAIL-mediated apoptosis. PloS one. 2011; 6(1):e16241.

33. Dittmer U, Peterson KE, Messer R, et al. Role of interleukin-4 (IL-4), IL-12, and gamma interferon in primary and vaccine-primed immune responses to Friend retrovirus infection. J Virol. 2001; 75(2):654-660.

34. Yao Y, Li W, Kaplan MH, et al. Interleukin (IL)-4 inhibits IL-10 to promote IL-12 production by dendritic cells. J Exp Med. 2005; 201(12):1899-1903.

35. Marsland BJ, Schmitz N, Kopf M. IL-4Ralpha signaling is important for CD8+ $\mathrm{T}$ cell cytotoxicity in the absence of CD4+ T cell help. Eur J Immunol. 2005; 35(5):1391-1398.

36. Heeren AM, Koster BD, Samuels $\mathrm{S}$, et al. High and interrelated rates of PD-L1+CD14+ antigen-presenting cells and regulatory $\mathrm{T}$ cells mark the microenvironment of metastatic lymph nodes from patients with cervical cancer. Cancer Immunol Res. 2015; 3(1):48-58.

37. Weiss JM, Subleski JJ, Back T, et al. Regulatory T cells and myeloid-derived suppressor cells in the tumor microenvironment undergo Fas-dependent cell death during IL-2/alphaCD40 therapy. J Immunol. 2014; 192(12):5821-5829.

38. Yamamoto K, Imamura H, Matsuyama Y, et al. AFP, AFP-L3, DCP, and GP73 as markers for monitoring treatment response and recurrence and as surrogate markers of clinicopathological variables of HCC. J Gastroenterol. 2010; 45(12):1272-1282.

39. Cheng J, Wang W, Zhang Y, et al. Prognostic role of pre-treatment serum AFP-L3\% in hepatocellular carcinoma: systematic review and meta-analysis. PLoS One. 2014; 9(1):e87011.

40. Li D, Mallory T, Satomura S. AFP-L3: a new generation of tumor marker for hepatocellular carcinoma. Clin Chim Acta. 2001; 313(1-2):15-19.

41. Chen $\mathrm{YL}, \mathrm{Chen} \mathrm{CH}, \mathrm{Hu} \mathrm{RH}$, et al. Elevated preoperative serum CA19-9 levels in patients with hepatocellular carcinoma is associated with poor prognosis after resection. ScientificWorldJournal. 2013; 2013:380797.

42. Kim HC, Nam CM, Jee $\mathrm{SH}$, et al. Normal serum aminotransferase concentration and risk of mortality from liver diseases: prospective cohort study. BMJ. 2004; 328(7446):983.

43. Schumacher TN, Schreiber RD. Neoantigens in cancer immunotherapy. Science. 2015; 348 (6230):69-74. 